\title{
Qualitative analysis of spinal intramedullary lesions using PET/CT
}

\author{
Kentaro Naito, MD, ${ }^{1}$ Toru Yamagata, MD, ${ }^{2}$ Hironori Arima, MD, Junya Abe, MD, ${ }^{1}$ \\ Naohiro Tsuyuguchi, MD, ${ }^{1}$ Kenji Ohata, MD, ${ }^{1}$ and Toshihiro Takami, MD ${ }^{1}$ \\ ${ }^{1}$ Department of Neurosurgery, Osaka City University Graduate School of Medicine; and 2Department of Neurosurgery, Osaka \\ City General Hospital, Osaka, Japan
}

\begin{abstract}
OBJECT Although the usefulness of PET for brain lesions has been established, few reports have examined the use of PET for spinal intramedullary lesions. This study investigated the diagnostic utility of PET/CT for spinal intramedullary lesions.

METHODS L-[methyl- $\left.{ }^{11} \mathrm{C}\right]-$ methionine (MET)- or $\left[{ }^{18} \mathrm{~F}\right]$-fluorodeoxyglucose (FDG)-PET/CT was performed in 26 patients with spinal intramedullary lesions. The region of interest $(\mathrm{ROI})$ within the spinal cord parenchyma was placed manually in the axial plane. Maximum pixel counts in the ROls were normalized to the maximum standardized uptake value $\left(S U V_{\max }\right)$ using subject body weight. For FDG-PET the SUV ${ }_{\max }$ was corrected for lean body mass (SUL $L_{\max }$ ) to exclude any influence of the patient's body shape. Each SUV was analyzed based on histopathological results after surgery. The diagnostic validity of the SUV was further compared with the tumor proliferation index using the MIB-1 monoclonal antibody (MIB-1 index).
\end{abstract}

RESULTS A total of 16 patients underwent both FDG-PET and MET-PET, and the remaining 10 patients underwent either FDG-PET or MET-PET. Pathological diagnoses included high-grade malignancy such as glioblastoma multiforme, anaplastic astrocytoma, or anaplastic ependymoma in 5 patients; low-grade malignancy such as hemangioblastoma, diffuse astrocytoma, or ependymoma in 12 patients; and nonneoplastic lesion including cavernous malformation in 9 patients. Both FDG and MET accumulated significantly in high-grade malignancy, and the SUL $L_{\max }$ and $S U V_{\max }$ correlated with the tumor proliferation index. Therapeutic response after chemotherapy or radiation in high-grade malignancy was well monitored. However, a significant difference in SUL $L_{\max }$ and $S U V_{\max }$ for FDG-PET and MET-PET was not evident between low-grade malignancy and nonneoplastic lesions.

CONCLUSIONS Spinal PET/CT using FDG or MET for spinal intramedullary lesions appears useful and practical, particularly for tumors with high-grade malignancy. Differentiation of tumors with low-grade malignancy from nonneoplastic lesions may still prove difficult. Further technological refinement, including the selection of radiotracer or analysis evaluation methods, is needed.

http://thejns.org/doi/abs/10.3171/2015.2.SPINE141254

KEY WORDS astrocytoma; cavernous malformation; ependymoma; positron emission tomography; spinal intramedullary tumor; technique

$\mathrm{P}$ OSITRON emission tomography (PET) can provide important information on tissue metabolism in a noninvasive manner and is now in practical use in the diagnostic field of tumor oncology. Both $\left[{ }^{18} \mathrm{~F}\right]$-fluorodeoxyglucose (FDG) and $\mathrm{L}$-[methyl- $\left.{ }^{11} \mathrm{C}\right]$-methionine (MET) have been used as radiotracers for identifying neoplasms. In the diagnosis of central nervous system tumors, the usefulness of these radiotracers for brain tumors has been established for evaluating malignancies, therapeutic response, or differentiation of tumor recurrence from tissue necrosis. ${ }^{1,2,7,10,20,22,23}$ However, investigations of spinal intramedullary tumors using PET remain sporadic, with only case reports or case series available to date. ${ }^{5,6,8,11,13}$, 15-17,18 PET diagnosis of spinal intramedullary tumors can-

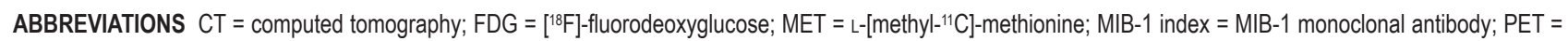
positron emission tomography; ROC = receiver operating characteristic; ROI = region of interest; SUL = standardized uptake value adjusted for lean body mass; SUV = standardized uptake value.

SUBMITTED December 14, 2014. ACCEPTED February 18, 2015

INCLUDE WHEN CITING Published online July 31, 2015; DOI: 10.3171/2015.2.SPINE141254.

DISCLOSURE The authors report no conflict of interest concerning the materials or methods used in this study or the findings specified in this paper. 
not be considered well established because of the relatively rare occurrence of this tumor type and the limited spatial resolution associated with spinal cord lesions. In the differential diagnosis of spinal intramedullary lesions, conventional imaging analyses using CT or MRI may not always provide qualitative information. Therefore, establishing qualitative imaging techniques for spinal intramedullary lesions is desirable. The present study attempts to qualitatively evaluate spinal intramedullary lesions using spinal FDG- or MET-PET/CT and to analyze clinical relationships with pathological diagnosis.

\section{Methods \\ Patients}

A total of 61 patients with spinal intramedullary lesions have been treated surgically at Osaka City University Hospital over the 5-year period from 2009 to 2014. FDG- or MET-PET/CT was conducted for further qualitative analysis after a comprehensive imaging evaluation prior to surgery in 26 of 61 patients (42.6\%). This study included 16 male and 10 female patients, ranging in age from 16 to 80 years (mean 47.6 years). Tumor location was cervical in 15 patients and thoracic in 11 patients.

\section{PET Analysis}

PET analysis in our institute has been described previously.,20,22,23 Briefly, PET/CT images were obtained using a Biograph 16 system (Siemens Medical Solutions). After 4 hours of fasting, $6 \mathrm{MBq} / \mathrm{kg}$ of MET or $370 \mathrm{MBq}$ of FDG was injected intravenously over 30 seconds. After a transmission scan was obtained, a static scan over 10 minutes was initiated 20 minutes after injection. Axial and transaxial resolutions of PET were 4.4 and $4.4 \mathrm{~mm}$ (full width at half maximum), respectively. The emission scan was reconstructed to a matrix of $336 \times 336$, and attenuation and scatter corrections were performed. Voxel size was $1.02 \times 1.02 \times 2 \mathrm{~mm}$. The region of interest (ROI) within the spinal cord was placed manually in the axial plane by 1 examiner (K.N.). ROIs within the spinal cord parenchyma were demarcated manually. Maximum pixel counts in ROIs were normalized to the maximum standardized uptake value $\left(\mathrm{SUV}_{\max }\right)$ using the patient's body weight. The $\mathrm{SUV}_{\max }$ was calculated according to the following formula: [(pixel count/pixel volume)/(injected radioisotope activity/body weight)] $\times$ calibration factor. For FDG-PET the SUV ${ }_{\max }$ was corrected for lean body mass $\left(\mathrm{SUL}_{\max }\right)$ in order to exclude any influence of body shape. ${ }^{19,24}$ Each SUL $_{\max }$ for FDG-PET or SUV ${ }_{\text {max }}$ for METPET was analyzed based on the pathological findings after surgery. The diagnostic validity of SUL ${ }_{\max }$ or $\mathrm{SUV}_{\max }$ was also compared with the tumor proliferation index using an MIB-1 monoclonal antibody (MIB-1 index). The diagnostic validity of the present study was examined using receiver operating characteristic (ROC) analysis. Independent variables and dependent dichotomous variables were considered to represent $\mathrm{SUL}_{\max }$ or $\mathrm{SUV}_{\text {max }}$ (for FDG-PET or MET-PET, respectively) and tumor malignancy. Highgrade or low-grade tumor malignancy was classified based on conventional pathological diagnosis. WHO Grade III or IV tumors or germ cell tumors were recognized to have high-grade malignancy, whereas WHO Grade I or II tumors were recognized to have low-grade malignancy.

\section{Statistical Analysis}

We used 1-way ANOVA followed by the Tukey-Kramer method to determine statistical differences between the $\mathrm{SUL}_{\max }$ and $\mathrm{SUV}_{\max }$ data for each group. Statistical analysis of correlations between the 2 variables was performed using Spearman's rank correlation coefficient. We used JMP version 9.0 software (SAS Institute) for statistical analysis. Values of $\mathrm{p}<0.05$ were considered significant.

\section{Statement of Ethics}

We certify that all applicable institutional and governmental regulations concerning the ethical use of clinical data were followed in the present study. This retrospective, comprehensive analysis of surgery-related outcomes was approved by the ethics committee of Osaka City University Graduate School of Medicine. Patient informed consent was obtained prior to PET examination.

\section{Results}

A total of 16 patients underwent both FDG-PET/CT and MET-PET/CT (hereafter referred to as FDG-PET and MET-PET for simplicity), and the remaining 10 patients underwent either FDG-PET or MET-PET. Pathological diagnoses included high-grade malignancy such as glioblastoma multiforme, anaplastic astrocytoma, or anaplastic ependymoma in 5 patients; low-grade malignancy such as hemangioblastoma, diffuse astrocytoma, or ependymoma in 12 patients; and nonneoplastic lesion including cavernous malformation in 9 patients. The characteristics of all 26 patients are summarized in Table 1.

\section{Clinical Significance of Spinal PET to Determine Tumor Malignancy}

The mean $\mathrm{SUL}_{\max }$ or $\mathrm{SUV}_{\text {max }}( \pm \mathrm{SE})$ for FDG-PET and MET-PET in patients with high-grade malignancy was $7.24 \pm 1.94$ and $4.18 \pm 1.13$, respectively (Fig. 1). The mean $\mathrm{SUL}_{\max }$ or $\mathrm{SUV}_{\text {max }}$ for FDG-PET and MET-PET in cases of low-grade malignancy $(2.24 \pm 0.23$ and $2.13 \pm 0.16$, respectively) was comparable to that of nonneoplastic lesions (1.97 \pm 0.55 and $2.00 \pm 0.55$, respectively) (Fig. 1). There was a significant difference in $\mathrm{SUL}_{\max }$ or $\mathrm{SUV}_{\max }$ between high- and low-grade malignancies, but not between low-grade malignancy and nonneoplastic lesions. Therefore, spinal PET/CT using FDG or MET appears to offer a practical method for identifying high-grade malignancy in cases of spinal intramedullary tumor.

\section{Clinical Correlation Between SUL ${ }_{\max } / \mathrm{SUV}_{\max }$ and Tumor Proliferation Index}

$\mathrm{SUL}_{\max }$ or $\mathrm{SUV}_{\max }$ of FDG-PET or MET-PET was compared with the MIB-1 index. A correlation was suggested between $\mathrm{SUL}_{\max }$ or $\mathrm{SUV}_{\max }$ and the MIB-1 index (Fig. 2). Higher values for $\mathrm{SUL}_{\max }$ or $\mathrm{SUV}_{\max }$ correlated well with a higher tumor proliferation index, suggesting that $\mathrm{SUL}_{\max }$ or $\mathrm{SUV}_{\max }$ may predict tumor malignancy before surgery. 
TABLE 1. Summary of patient characteristics, grouped according to tumor malignancy

\begin{tabular}{|c|c|c|c|c|c|c|c|c|}
\hline Patient No. & Age (yrs) & Sex & Spine Level & Pathological Diagnosis & Tumor Malignancy & MIB-1 Index (\%) & FDG SUL $L_{\max }$ & MET SUV ${ }_{\max }$ \\
\hline 1 & 27 & M & Thoracic & GBM & High & 11 & - & 1.64 \\
\hline 3 & 37 & $M$ & Cervical & Anaplastic astrocytoma & High & 30 & 7.879 & 6.547 \\
\hline 5 & 37 & $\mathrm{~F}$ & Thoracic & Germ cell tumor & High & 15 & 4.007 & 3.018 \\
\hline 20 & 25 & M & Cervical & Anaplastic ependymoma & High & 16 & 4.616 & - \\
\hline 26 & 36 & $\mathrm{~F}$ & Cervical & Anaplastic ependymoma & High & 20 & 12.468 & 5.52 \\
\hline Mean & & & & & & 18.4 & 7.24 & 4.18 \\
\hline 6 & 66 & M & Thoracic & Hemangioblastoma & Low & - & 1.232 & 1.093 \\
\hline 9 & 46 & $\mathrm{~F}$ & Cervical & Ependymoma & Low & 1 & 1.142 & - \\
\hline 10 & 19 & M & Cervical & Pilocytic astrocytoma & Low & 5 & 3.169 & 2.93 \\
\hline 11 & 48 & M & Cervical & Hemangioblastoma & Low & 12 & 2.280 & - \\
\hline 12 & 44 & $\mathrm{~F}$ & Thoracic & Astrocytoma & Low & 15 & 2.399 & 2.356 \\
\hline 14 & 57 & $\mathrm{M}$ & Cervical & Ependymoma & Low & 1 & 4.085 & 2.215 \\
\hline 15 & 16 & M & Thoracic & Astrocytoma & Low & 8 & 2.945 & 1.907 \\
\hline 17 & 65 & $\mathrm{~F}$ & Cervical & Ependymoma & Low & 1.5 & 2.920 & 1.921 \\
\hline 18 & 69 & $\mathrm{M}$ & Thoracic & Hemangioblastoma & Low & 1.5 & 1.943 & 2.698 \\
\hline 19 & 80 & M & Thoracic & Ependymoma & Low & 2 & 2.211 & 1.965 \\
\hline 22 & 53 & $\mathrm{~F}$ & Cervical & Ependymoma & Low & 1 & 1.323 & - \\
\hline 24 & 39 & $\mathrm{~F}$ & Thoracic & Hemangioblastoma & Low & 1 & 1.272 & 2.068 \\
\hline Mean & & & & & & 4.5 & 2.24 & 2.13 \\
\hline 2 & 28 & M & Thoracic & Langerhans cell histiocytosis & Nonneoplastic & - & 1.848 & 1.977 \\
\hline 4 & 31 & $\mathrm{~F}$ & Thoracic & Myelomalacia & Nonneoplastic & - & 1.287 & - \\
\hline 7 & 27 & M & Cervical & $\mathrm{CM}$ & Nonneoplastic & - & 1.786 & - \\
\hline 8 & 74 & $\mathrm{~F}$ & Cervical & $\mathrm{CM}$ & Nonneoplastic & - & 1.866 & 1.377 \\
\hline 13 & 62 & M & Cervical & Myelomalacia & Nonneoplastic & - & - & 2.031 \\
\hline 16 & 63 & $\mathrm{~F}$ & Cervical & $\mathrm{CM}$ & Nonneoplastic & - & 1.113 & 1.073 \\
\hline 21 & 69 & M & Thoracic & Myelitis & Nonneoplastic & - & 1.249 & - \\
\hline 23 & 58 & M & Cervical & $\mathrm{CM}$ & Nonneoplastic & - & 2.060 & - \\
\hline 25 & 61 & M & Cervical & Sarcoidosis & Nonneoplastic & - & 4.572 & 3.54 \\
\hline Mean & & & & & & - & 1.97 & 2.00 \\
\hline
\end{tabular}

$\mathrm{CM}=$ cavernous malformation; $\mathrm{GBM}=$ glioblastoma multiforme; $-=$ not applicable .

\section{ROC Analysis}

ROC curves for FDG-PET and MET-PET are shown in Fig. 3. An increase in $\mathrm{SUL}_{\max }$ or $\mathrm{SUV}_{\max }$ is a valid diagnostic tool for differentiating high-grade malignancy from

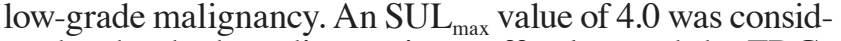
ered to be the best diagnostic cutoff value, and the FDGPET modality exhibited $100 \%$ sensitivity and $91.7 \%$ specificity. The predictive probability of a positive FDG-PET test was $80 \%$, and the predictive probability of a negative test was $100 \%$. An $\mathrm{SUV}_{\max }$ of 3.0 was considered to be the best diagnostic cutoff value, and the MET-PET modality exhibited $75 \%$ sensitivity and $100 \%$ specificity. The predictive probability of a positive MET-PET test was $100 \%$, and the predictive probability of a negative test was $90 \%$.

\section{Illustrative Cases}

Case 3

A 37-year old male presented with an acute progression of sensory disturbance in the left upper extremity. Cervical MRI showed spinal cord swelling with intramedullary hyperintensity on T2-weighted imaging and heteroge- neous enhancement on T1-weighted imaging (Fig. 4). Spinal PET with FDG and MET indicated high accumulation within the lesion with $\mathrm{SUL}_{\max }$ and $\mathrm{SUV}_{\max }$ values of 7.879 and 6.547, respectively. Surgical verification of the tumor suggested an invasive nature of the anaplastic tumor. Pathological diagnosis of the tumor after surgery revealed an anaplastic astrocytoma with an MIB-1 index of 30\%.

\section{Case 5}

A 37-year old female presented with an acute progression of gait disturbance. Thoracic MRI showed spinal cord swelling with intramedullary hyperintensity on T2weighted imaging and heterogeneous enhancement on T1-weighted imaging (Fig. 5). Spinal PET with FDG and MET indicated high accumulation within the lesion, with $\mathrm{SUL}_{\max }$ and $\mathrm{SUV}_{\max }$ values of 4.007 and 3.018, respectively. Surgical verification of the tumor suggested an invasive nature of the anaplastic tumor. Pathological diagnosis of the tumor after surgery revealed a germ cell tumor with an MIB-1 index of $15 \%$. Brain MRI revealed no other lesions, so the germ cell tumor was considered to have a spinal 

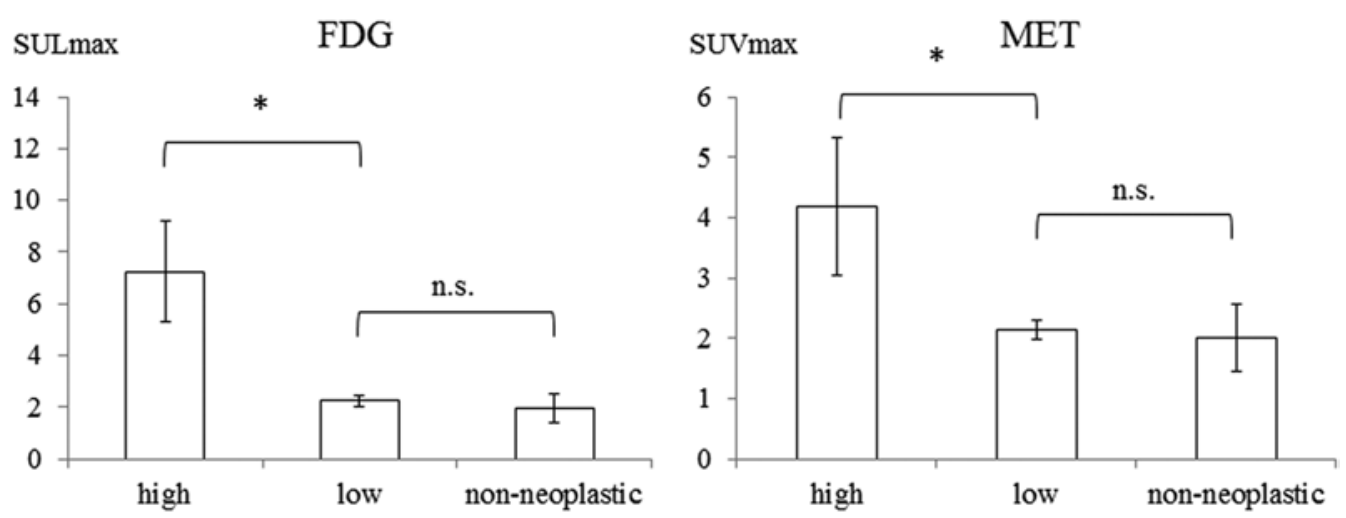

FIG. 1. Graphs showing the mean SUL ${ }_{\max }$ from FDG-PET (left) and the SUV ${ }_{\max }$ from MET-PET (right). Values in high-grade malignancy are significantly higher than those in low-grade malignancy, whereas no significant difference is evident between low-grade malignancy and nonneoplastic lesions. ${ }^{*} p<0.05$. n.s. = not significant.

intramedullary origin. Three courses of chemotherapy using ifosfamide, carboplatin, and etoposide (ICE regimen) were administered and followed by whole-brain and spinal irradiation. Sequential PET analysis indicated satisfactory remission of the spinal intramedullary lesion.

\section{Discussion}

The pathophysiological characterization of spinal cord metabolism may provide insights into the differential diagnosis of spinal intramedullary lesions. However, quantification of the spinal cord using PET is challenging because of the small cord size and osseous contamination, even under benign conditions, compared with the brain. Normal metabolic patterns in the healthy spinal cord remain under investigation and are not yet fully understood. , $^{3,9,12,14} \mathrm{Nu}-$ merous PET studies for brain tumors have been reported, and the usefulness of this modality in qualitative imaging diagnosis is well established. . $2,7,10,20,22,23$ The diagnostic validity of PET for patients with brain tumors has been established for evaluating tumor malignancy, therapeutic response, or differentiation of tumor recurrence from tissue necrosis. However, few studies on spinal intramedullary le-

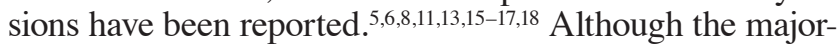
ity of previously published studies are illustrative case re- ports, the findings suggest that spinal PET may play a role in the clinical diagnosis of spinal intramedullary lesions by helping to identify diagnostically troublesome lesions based on metabolic activity. Wilmshurst et al. conducted a prospective study to investigate the use of FDG- and MET-PET for detection of spinal intramedullary tumors in 14 patients over a 5-year period. ${ }^{25}$ The study consisted of patients with astrocytoma, ependymoma, mixed ependymoma and astrocytoma, schwannoma, and ganglioglioma. The authors studied 7 patients who underwent FDG-PET and 1 patient who underwent MET-PET prior to surgery. Other patients were studied after surgery and/or radiation. The authors stated that PET did not provide additional useful information in their small group of patients because all tumors exhibited low-grade malignancy, and the limited spatial resolution of PET did not allow high-quality imaging analysis. The authors concluded that a prospective study using a larger number of patients with a wider range of tumor types was required, but conducting such a study may be difficult to achieve given the rarity of spinal cord tumors. Tomura et al. also used spinal PET to examine 9 patients with spinal intramedullary tumors. ${ }^{21}$ These authors showed that both FDG and MET accumulated in ependymoma (excluding a myxopapillary ependymoma) and
FDG

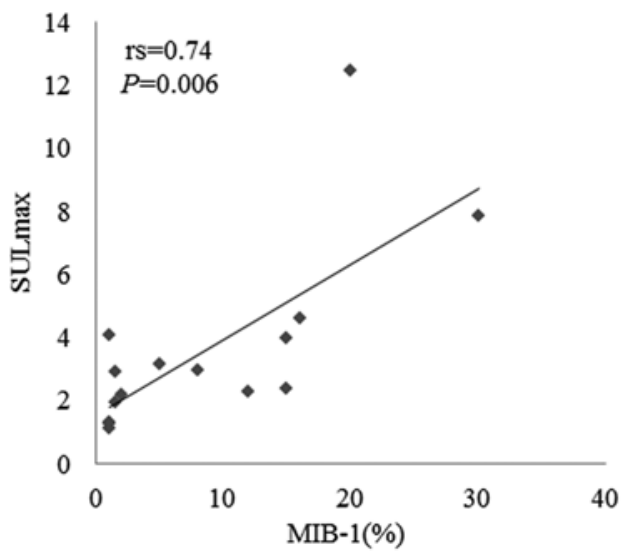

MET

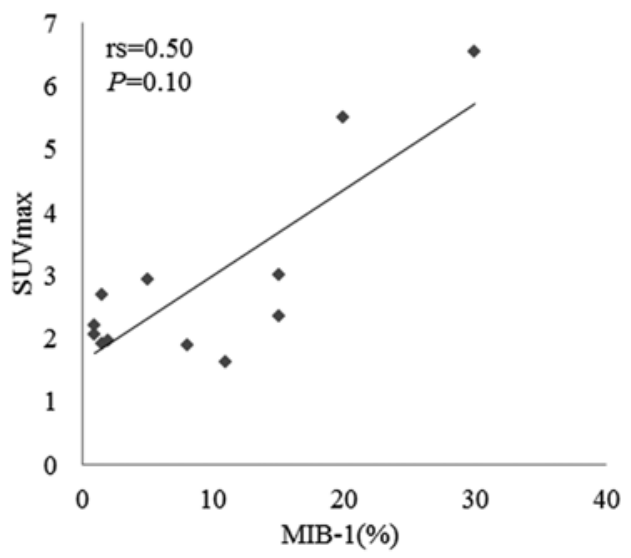

FIG. 2. Graphs showing a correlation between the SUL $L_{\max }$ from FDG-PET (left) or the SUV $\mathrm{max}_{\max }$ from MET-PET (right) and the tumor proliferation index. 


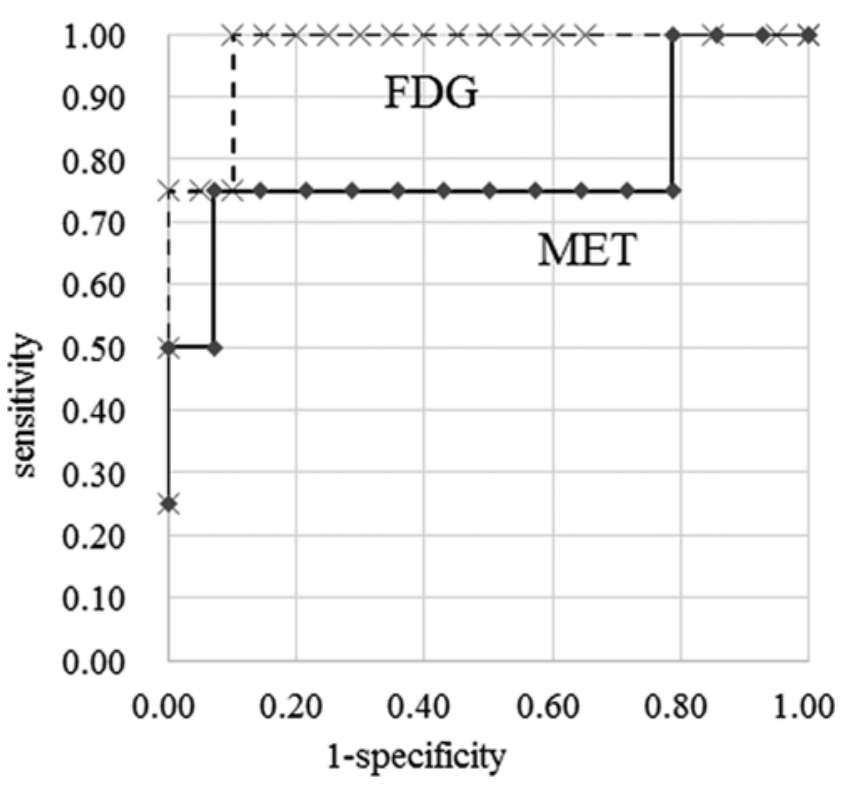

FIG. 3. ROC curves for FDG-PET and MET-PET. An increase in SUL $\max$ or SUV ${ }_{\max }$ is a valid diagnostic indicator for differentiating tumors with high-grade malignancy from tumors with low-grade malignancy. An SUL $L_{\max }$ of 4.0 was considered to be the best diagnostic cutoff value for FDG-PET with $100 \%$ sensitivity and $91.7 \%$ specificity. An SUV max $_{\text {of }} 3.0$ was considered to be the best diagnostic cutoff value for MET-PET with $75 \%$ sensitivity and $100 \%$ specificity.

to a large degree in anaplastic astrocytoma. The authors also reported that FDG can accumulate in tumors with hemorrhage. In their study, 3 tumors with hemorrhage, including a cavernous malformation, showed increased accumulation of FDG. All 3 tumors with hemorrhage exhibited microscopic hemorrhages without evidence of subacute hemorrhage. Although the mechanism of FDG accumulation in tumors with hemorrhage was unknown, the authors speculated that it may be related to mononuclear perivascular infiltrates, gliosis, and activated macrophages. In the present study, we demonstrated that both FDG and MET accumulate significantly in spinal intramedullary tumors classified as high-grade malignancies and that SUV values correlate significantly with the tumor proliferation index. Therapeutic response after chemotherapy or radiation in high-grade malignancies was well monitored. However, difficulties can still be encountered when differentiating low-grade malignancies from nonneoplastic lesions. The present findings suggest that nonneoplastic lesions do not always demonstrate a low $\mathrm{SUL}_{\max }$ or $\mathrm{SUV}_{\max }$ in both FDGand MET-PET. Accumulation of FDG or MET in the spinal cord can be affected by inflammatory or glial reactions.

The present study appears to be the first attempt to perform a quantitative analysis of spinal intramedullary lesions using spinal PET/CT, which is more accurate and informative than ordinary PET. However, several limitations must be considered. The first limitation is the heterogeneity of the tumor pathology in a small number of patients. A larger number of patients would be desirable in order to reach definitive conclusions regarding correlations between $\mathrm{SUL}_{\max }$ or $\mathrm{SUV}_{\max }$ and tumor malignancy. The second limitation is the lack of data regarding FDG and MET accumulation in the normal healthy spinal cord. Another issue to be resolved is how accurately postoperative PET/CT can illustrate subtotal resection when grosstotal resection is thought to have been accomplished. In the present study, PET/CT was not routinely performed after surgery, except in cases of high-grade malignancy. It may be difficult to detect the small residual tumor on postoperative MRI because the resolution of PET/CT on such
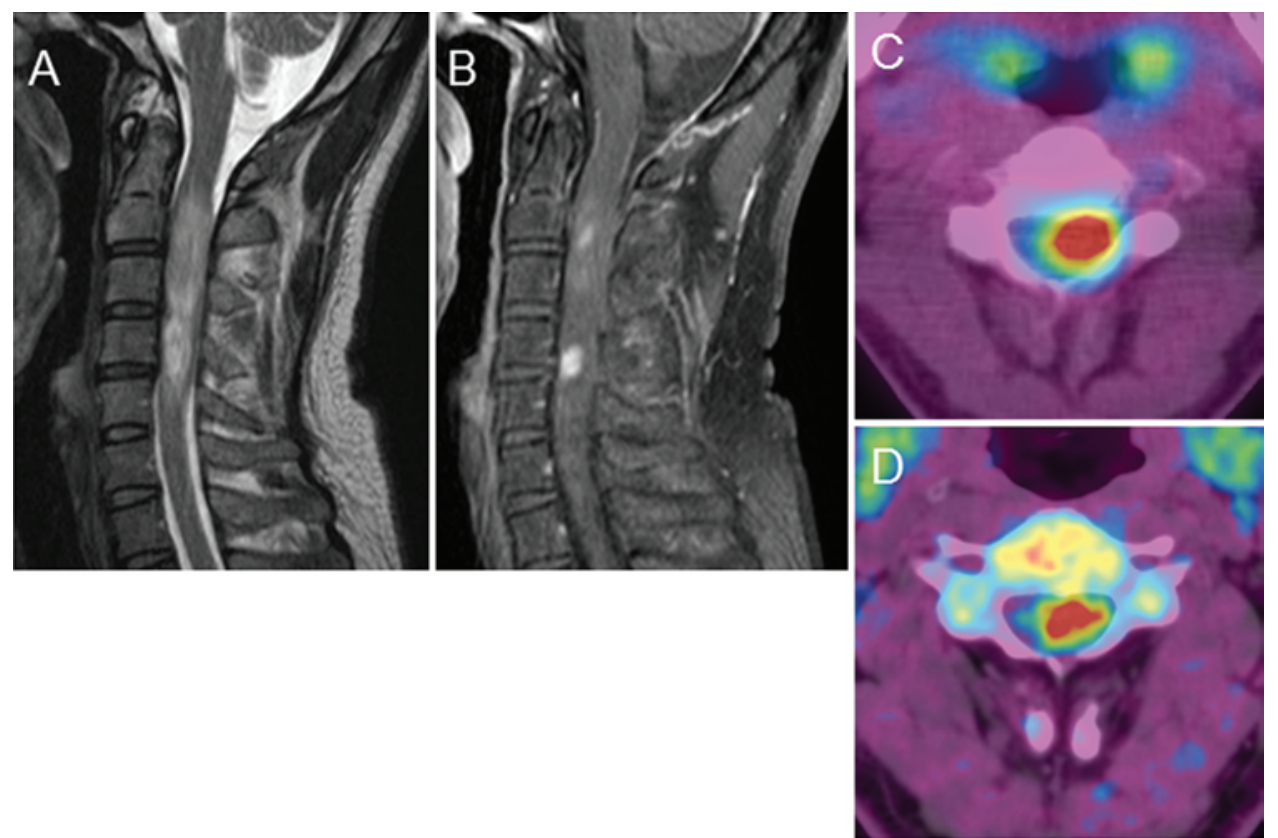

FIG. 4. Illustrative case of patient with spinal anaplastic astrocytoma. A T2-weighted MR image (A) before surgery shows severe swelling of the spinal cord with intramedullary signal change. Enhanced T1-weighted MR image (B) before surgery shows abnormal intramedullary enhancement. FDG-PET/CT (C) and MET-PET/CT scans (D) before surgery show high accumulations within the spinal cord. 

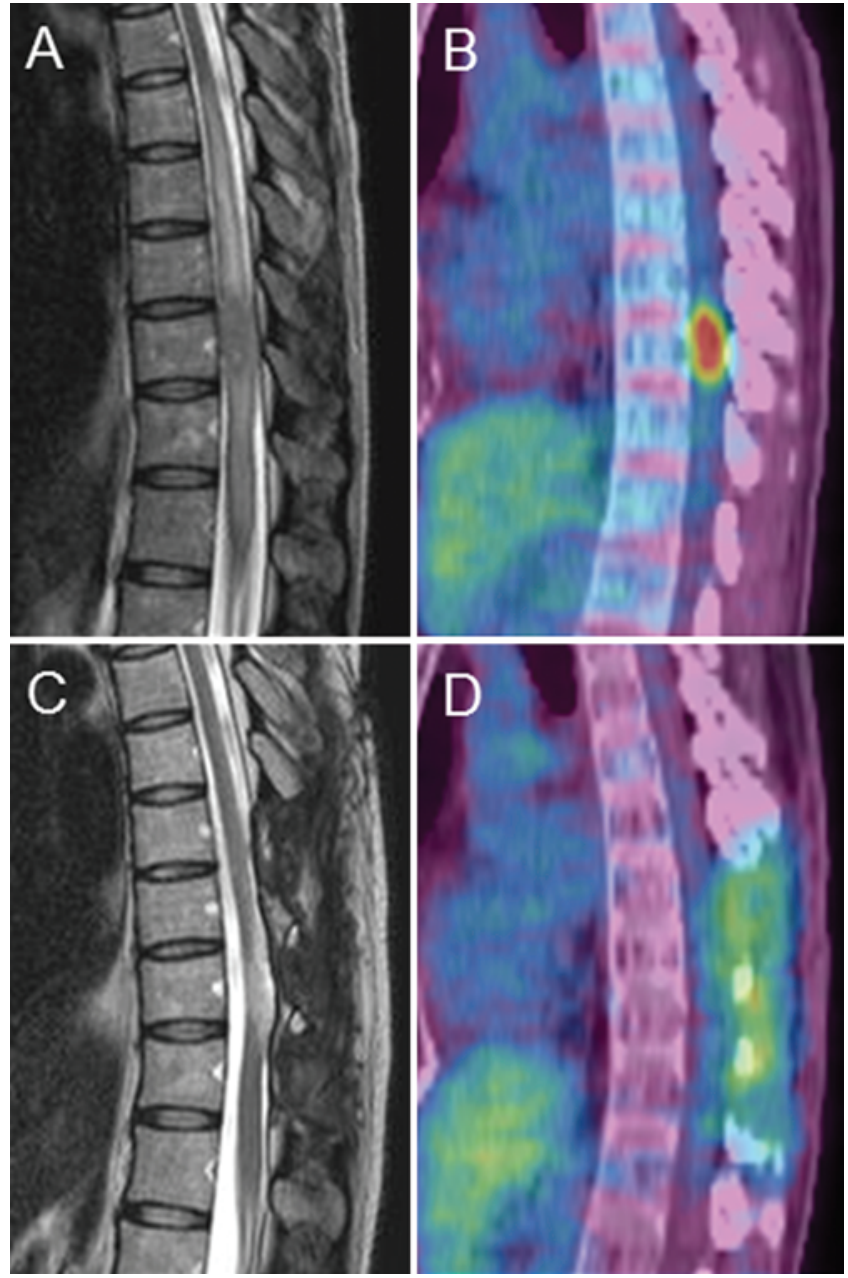

FIG. 5. Illustrative case of patient with spinal germ cell tumor. A: T2weighted MR image before surgery shows severe swelling of the spinal cord with intramedullary signal change. B: FDG-PET/CT before surgery shows high accumulation within the spinal cord. C: T2-weighted MR image after chemoradiotherapy shows atrophic change of the spinal cord. D: FDG-PET/CT after chemoradiotherapy shows a marked decrease in FDG accumulation within the spinal cord.

a small lesion is still limited. Finally, although in the present study we were unable to confirm the clinical significance of spinal PET/CT in differentiating low-grade malignancies from nonneoplastic lesions, having such clinical information on tumor malignancy before treatment may help physicians judge the surgical indication or strategy.

\section{Conclusions}

PET can provide important information on tissue metabolism in a noninvasive manner. This study of spinal PET/CT demonstrated that both FDG and MET accumulate significantly in spinal intramedullary tumors classified as high-grade malignancies and that SUVs correlate significantly with the tumor proliferation index. Therapeutic response after chemotherapy or radiation in high-grade malignancy was well monitored. However, difficulties remain in differentiating low-grade malignancies from nonneoplastic lesions. We believe that spinal PET/CT may have an important role to play in clinical diagnosis by helping to identify diagnostically troublesome lesions based on metabolic activity, although further technological refinements, such as the selection of radiotracer and the evaluation methods, are needed.

\section{References}

1. Ceyssens S, Van Laere K, de Groot T, Goffin J, Bormans G, Mortelmans L: [11C]methionine PET, histopathology, and survival in primary brain tumors and recurrence. AJNR Am J Neuroradiol 27:1432-1437, 2006

2. Derlon JM, Bourdet C, Bustany P, Chatel M, Theron J, Darcel F, et al: [11C]L-methionine uptake in gliomas. Neurosurgery 25:720-728, 1989

3. Di Chiro G, Oldfield E, Bairamian D, Patronas NJ, Brooks RA, Mansi L, et al: Metabolic imaging of the brain stem and spinal cord: studies with positron emission tomography using 18F-2-deoxyglucose in normal and pathological cases. J Comput Assist Tomogr 7:937-945, 1983

4. Do BH, Mari C, Tseng JR, Quon A, Rosenberg J, Biswal S: Pattern of 18F-FDG uptake in the spinal cord in patients with non-central nervous system malignancy. Spine (PhilaPa 1976) 36:E1395-E1401, 2011

5. Gwak HS, Youn SM, Chang U, Lee DH, Cheon GJ, Rhee $\mathrm{CH}$, et al: Usefulness of (18)F-fluorodeoxyglucose PET for radiosurgery planning and response monitoring in patients with recurrent spinal metastasis. Minim Invasive Neurosurg 49:127-134, 2006

6. Higano S, Shishido F, Nagashima M, Tomura N, Murakami $\mathrm{M}$, Inugami A, et al: PET evaluation of spinal cord tumor using 11C-methionine. J Comput Assist Tomogr 14:297-299, 1990

7. Ikeda H, Tsuyuguchi N, Kunihiro N, Ishibashi K, Goto T, Ohata K: Analysis of progression and recurrence of meningioma using (11)C-methionine PET. Ann Nucl Med 27:772780,2013

8. Jayasundera MV, Thompson JF, Fulham MJ: Intramedullary spinal cord metastasis from carcinoma of the lung: detection by positron emission tomography. Eur J Cancer 33:508509, 1997

9. Kamoto Y, Sadato N, Yonekura Y, Tsuchida T, Uematsu H, Waki A, et al: Visualization of the cervical spinal cord with FDG and high-resolution PET. J Comput Assist Tomogr 22:487-491, 1998

10. Kato T, Shinoda J, Oka N, Miwa K, Nakayama N, Yano H, et al: Analysis of 11C-methionine uptake in low-grade gliomas and correlation with proliferative activity. AJNR Am J Neuroradiol 29:1867-1871, 2008

11. Komori T, Delbeke D: Leptomeningeal carcinomatosis and intramedullary spinal cord metastases from lung cancer: detection with FDG positron emission tomography. Clin Nucl Med 26:905-907, 2001

12. McCarville MB, Monu N, Smeltzer MP, Li CS, Laningham $\mathrm{FH}$, Morris EB, et al: PET-CT of the normal spinal cord in children. Acad Radiol 16:881-885, 2009

13. Meltzer CC, Townsend DW, Kottapally S, Jadali F: FDG imaging of spinal cord primitive neuroectodermal tumor. $\mathbf{J}$ Nucl Med 39:1207-1209, 1998

14. Nakamoto Y, Tatsumi M, Hammoud D, Cohade C, Osman MM, Wahl RL: Normal FDG distribution patterns in the head and neck: PET/CT evaluation. Radiology 234:879-885, 2005

15. Nguyen NC, Sayed MM, Taalab K, Osman MM: Spinal cord metastases from lung cancer: detection with F-18 FDG PET/ CT. Clin Nucl Med 33:356-358, 2008

16. Poggi MM, Patronas N, Buttman JA, Hewitt SM, Fuller B: Intramedullary spinal cord metastasis from renal cell carcinoma: detection by positron emission tomography. Clin Nucl Med 26:837-839, 2001 
17. Sasajima T, Mineura K, Itoh Y, Kowada M, Hatazawa J, Ogawa T, et al: Spinal cord ependymoma: a positron emission tomographic study with (11C-methyl)-L-methionine. Neuroradiology 38:53-55, 1996

18. Shimizu T, Saito N, Aihara M, Kurihara H, Nakazato Y, Ueki K, et al: Primary spinal oligoastrocytoma: a case report. Surg Neurol 61:77-81, 2004

19. Sugawara Y, Zasadny KR, Neuhoff AW, Wahl RL: Reevaluation of the standardized uptake value for FDG: variations with body weight and methods for correction. Radiology 213:521-525, 1999

20. Terakawa Y, Tsuyuguchi N, Iwai Y, Yamanaka K, Higashiyama S, Takami T, et al: Diagnostic accuracy of 11C-methionine PET for differentiation of recurrent brain tumors from radiation necrosis after radiotherapy. J Nucl Med 49:694699, 2008

21. Tomura N, Ito Y, Matsuoka H, Saginoya T, Numazawa SI, Mizuno Y, et al: PET findings of intramedullary tumors of the spinal cord using [18F] FDG and [11C] methionine. AJNR Am J Neuroradiol 34:1278-1283, 2013

22. Tsuyuguchi N, Sunada I, Iwai Y, Yamanaka K, Tanaka K, Takami T, et al: Methionine positron emission tomography of recurrent metastatic brain tumor and radiation necrosis after stereotactic radiosurgery: is a differential diagnosis possible? J Neurosurg 98:1056-1064, 2003

23. Tsuyuguchi N, Takami T, Sunada I, Iwai Y, Yamanaka K, Tanaka K, et al: Methionine positron emission tomography for differentiation of recurrent brain tumor and radiation necrosis after stereotactic radiosurgery-in malignant glioma. Ann Nucl Med 18:291-296, 2004

24. Wahl RL, Jacene H, Kasamon Y, Lodge MA: From RECIST to PERCIST: Evolving considerations for PET response criteria in solid tumors. J Nucl Med 50 (Suppl 1):122S-150S, 2009

25. Wilmshurst JM, Barrington SF, Pritchard D, Cox T, Bullock $\mathrm{P}$, Maisey M, et al: Positron emission tomography in imaging spinal cord tumors. J Child Neurol 15:465-472, 2000

\section{Author Contributions}

Conception and design: Takami, Naito. Acquisition of data: Naito, Tsuyuguchi. Analysis and interpretation of data: Takami, Naito. Drafting the article: Takami, Naito. Critically revising the article: Takami, Naito. Reviewed submitted version of manuscript: Takami, Ohata. Approved the final version of the manuscript on behalf of all authors: Takami. Statistical analysis: Takami. Administrative/technical/material support: Yamagata, Arima, Abe, Tsuyuguchi. Study supervision: Takami, Ohata.

\section{Correspondence}

Toshihiro Takami, Department of Neurosurgery, Osaka City University Graduate School of Medicine, 1-4-3 Asahi-machi, Abenoku, Osaka 545-8585, Japan. email: ttakami@med.osaka-cu.ac.jp. 